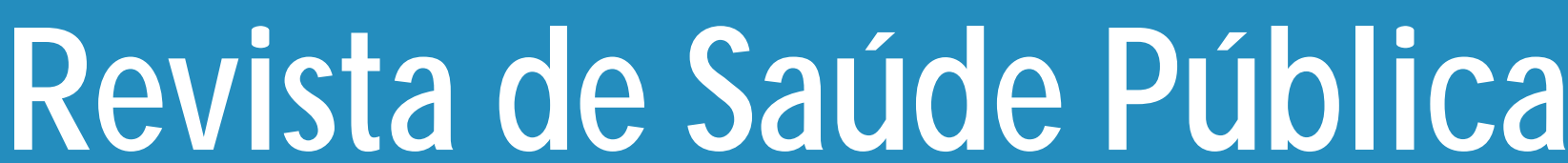
Journal of Public Health

\title{
Avaliação de serviço de atenção a crianças víti- mas de violência doméstica
}

\section{Evaluating a support program for children victim of domestic violence}

\section{H ebe S G onçalves, Ana L Ferreira e Mario JV Marques}

Instituto de Puericultura e Pediatria Martagão Gesteira da Universidade Federal do Rio de Janeiro. Rio de Janeiro, RJ - Brasil 


\title{
Avaliação de serviço de atenção a crianças vítimas de violência doméstica
}

\section{Evaluating a support program for children victim of domestic violence}

\author{
Hebe S Gonçalves, Ana L Ferreira e Mario JV Marques \\ Instituto de Puericultura e Pediatria Martagão Gesteira da Universidade Federal do Rio de Janeiro. Rio \\ de Janeiro, RJ - Brasil
}

\section{Descritores}

Violência doméstica. Maus-tratos infantis. Serviço social. Estrutura dos serviços. Bem-estar da criança.

\section{Keywords}

Domestic violence. Child abuse. Social work. Services structure. Child welfare.

\section{Resumo}

\section{Objetivo}

A violência contra a criança tem sido objeto de ação de várias instituições brasileiras. Poucos são os estudos sobre a estrutura e o funcionamento de serviços de assistência às vítimas. Realizou-se pesquisa para avaliar a dinâmica de atendimento do Programa SOS Criança e para oferecer subsídios para a avaliação de serviços que prestem atendimento similar.

\section{Métodos}

Foi feito um estudo de corte transversal de 976 formulários de registro de dados, relativos a casos atendidos pelo SOS Criança concluídos em 1993. Foram analisados: o tipo de serviço solicitado, os procedimentos de investigação da denúncia, a duração do acompanhamento e os encaminhamentos a outras instituições.

\section{Resultados}

Dentre os casos analisados, 587 referiam-se a denúncias de maus-tratos: $38,7 \%$ de abuso físico, 27,7\% de negligência, 26,3\% de abuso psicológico e 7,3\% de abuso sexual. A maioria das denúncias (32,5\%) foi feita por familiares das crianças. A investigação dos casos durou entre 126 e 212 dias, exigindo da equipe do Programa SOS uma média de 2,7 a 4,6 ações por caso investigado. A maioria dos casos foi encaminhada a outras instituições, principalmente às varas da Infância e da Família $(44,0 \%)$.

\section{Conclusão}

Detectou-se necessidade de haver capacitação permanente de pessoal e integração do Programa SOS Criança à rede de serviços sociais e de saúde.

\footnotetext{
Abstract

Introduction

Domestic violence against children has been a subject of concern to many Brazilian institutions, though there are few studies about the services offered to the community. The aim of this study is to evaluate administrative and operational aspects of the SOS Criança and provide insight to similar programs with comparative data. Methods

A cross-sectional study of 976 data sheets of investigated cases until 1993 was conducted. Study variables were: characteristics of the support program required, proceedings to investigate reported cases, follow-up duration of reported cases, and referrals to other institutions.
} 


\begin{abstract}
Results
Out of 976 data sheets analyzed, 587 involved domestic violence against children: $38.7 \%$ cases of physical abuse, $27.7 \%$ of neglect, $26.3 \%$ of psychological abuse and $7.3 \%$ of sexual abuse. Most of the complaints (32.5\%) came from family members of victimized children. The program's investigation process took between 126 to 212 days. Each investigated case demanded an average of 2.7 to 4.6 procedures. The majority of the cases (44.0\%) were referred to a law court. This study emphasizes the need of a computerized database for optimizing the services provided and the victims' follow-up. It also suggests the need of ongoing staff training and development of broader and stronger connections to the social and health services.
\end{abstract}

\section{INTRODUÇÃO}

A violência é uma questão que permeia a condição humana. Sua visibilidade tanto pode ser correlacionada às formas através das quais se manifesta quanto à capacidade da sociedade em efetivamente percebê-la. Em 1962, Kempe et al. ${ }^{4}$ mostraram para a sociedade uma forma de violência até então oculta no interior dos lares: a violência contra a criança.

Em meados da década de 80, a sociedade brasileira busca dar resposta a essa questão. A fundação do Centro Regional de Atenção aos Maus-Tratos na Infância (Crami), em Campinas, em 1985, e da Associação Brasileira Multiprofissional de Proteção à Infância e à Adolescência (Abrapia), no Rio de Janeiro, em 1988, visou basicamente prestar serviços às crianças vítimas de violência. Desde então, outros serviços somaram-se àquelas iniciativas.

$\mathrm{Na}$ área da violência contra a criança e o adolescente, uma das questões pouco tratadas no Brasil é a análise da estrutura dos serviços, necessária não apenas para sua avaliação interna como também para que a experiência tornada pública sirva àqueles que desejam criar serviços similares. Deslandes ${ }^{2,3}$ analisou a atuação do Crami pelos casos atendidos entre 1988 e 1992. Cunha ${ }^{1}$ estudou os casos concluídos na Abrapia no período de 1996, no qual fornece diversos elementos de comparação que serão explorados ao longo do trabalho.

O presente trabalho tem por objetivo avaliar a dinâmica de atendimento do SOS Criança com base nos procedimentos técnicos e administrativos realizados a partir da denúncia de maus-tratos contra a criança. Além disso, o trabalho pretende disponibilizar dados para estudos comparativos com instituições que ofereçam serviços similares.

\section{MÉTODOS}

Foram analisados 976 formulários de registro de dados, referentes a casos concluídos durante o ano de 1993, que haviam sido encaminhados à Abrapia no período de outubro de 1991 a dezembro de 1993*. Verificou-se, caso a caso, a dinâmica de funcionamento do SOS Criança, desde a notificação até a respectiva conclusão. Os formulários de registro continham todos os dados relativos a cada caso, desde o telefonema inicial até o instante em que a ação institucional era dada por concluída. Assim, o uso dos formulários originais como fonte de informação primária cobre a totalidade dos dados registrados sobre cada um do total de casos estudados.

Os dados dos formulários foram transcritos em programa especialmente criado com base no Epi Info, versão 6.04, a partir da análise inicial de 100 formulários (cerca de 10\% da amostra). O banco de dados criado procurou ser fiel aos registros originais, restringindo ao máximo a interpretação dos dados disponíveis nos formulários. A transcrição dos dados para o banco informatizado foi feita por apenas duas das pesquisadoras, na tentativa de assegurar a confiabilidade da transcrição, assim como a fidedignidade da interpretação, onde esta fosse imprescindível.

\section{Funcionamento do Programa}

A Abrapia é uma organização não governamental que desenvolve e executa programas de defesa dos direitos da criança e do adolescente, em particular no que se refere à violência doméstica. Atualmente, atua através de sete programas, um dos quais o SOS Criança, que recebe comunicações de maus-tratos praticados contra crianças e adolescentes. Desenvolve uma série de procedimentos que têm por objetivo confirmar, ou descartar, a ocorrência de maus-tratos e encaminhar crianças, adolescentes e seus familiares para instituições oficiais ou recursos da comunidade, de acordo com as necessidades detectadas durante a avaliação do caso. Em algumas situações, o caso é concluído na própria Abrapia; em outras, os técnicos indicam a necessidade de intervenção de outras instituições, ocasião em que o

* O trabalho de Cunha' utiliza a mesma técnica de amostragem, diferindo apenas no período de coleta de dados: são analisados pela autora casos de maus-tratos concluídos no ano de 1996, cobrindo denúncias levadas a Instituição entre novembro de 1992 e dezembro de 1996. Foram excluídas de sua amostra os casos procedentes da Baixada Fluminense e outras áreas do Estado do Rio de Janeiro, os atendimentos que se iniciaram em 1996 e continuaram a ser atendidos no ano de 1997 e ainda os casos que foram encaminhados a outras instituições, que prosseguiram com o atendimento. 
encaminhamento é que marca a conclusão do caso. Essa diferença é condicionada pela própria dinâmica dos casos atendidos.

Os serviços do SOS Criança são amplamente divulgados, e uma linha de telefone é colocada à disposição da população e de profissionais para encaminhamento de denúncias. Esses telefonemas são registrados como denúncias de maus-tratos. Os usuários entram em contato com o SOS Criança também para solicitar informações sobre questões que não se caracterizam como denúncias, contatos que a Abrapia convencionou chamar pedidos de orientação.

O SOS Criança considera que um caso de maus-tratos tem início a partir da respectiva notificação, momento em que são coletados os dados que orientam todo o processo de investigação subsequiente. $\mathrm{Na}$ medida em que a investigação vai apresentando indícios de que a denúncia tem fundamento, os procedimentos de verificação tornam-se mais complexos; por essa razão, há diferenças importantes nos procedimentos entre as denúncias de maus-tratos que foram ou não confirmadas. A partir da notificação, o SOS Criança mantém contatos com o suposto agressor (ou agressora) e/ou com a suposta vítima (ou vítimas). Usualmente, a denúncia gera o envio de uma correspondência ao suposto agressor ou à família da vítima, com a qual é agendada uma entrevista na sede da Abrapia. Caso não haja resposta a duas convocações consecutivas, os técnicos procedem a uma visita domiciliar. Esta pode ainda ser realizada após a entrevista (se forem identificadas circunstâncias que requeiram investigação mais acurada) ou logo após a denúncia, independente do convite escrito (quando a gravidade do caso indicar necessidade de intervenção imediata).

A equipe do SOS, no período estudado, contava com a participação de psicólogos e assistentes sociais, atuando em regime de plantão, além do apoio técnico de médicos e advogados. O técnico responsável pela investigação da denúncia é aquele que a acolhe durante o plantão, independente de sua especialidade. Nos casos em que o técnico responsável identifica a necessidade de parecer de uma outra especialidade, este profissional é chamado a participar.

\section{RESULTADOS}

Nos formulários analisados, 587 referiam-se a denúncias de maus-tratos e 389 a pedidos de orientação.

\section{Pedidos de orientação}

Os familiares das crianças e adolescentes concentraram o maior número de pedidos de orientação: tios, avós, pais, madrastas e padrastos foram responsáveis por $45,0 \%$ dos telefonemas; vizinhos $(8,7 \%)$ e amigos da família $(3,3 \%)$ foram outros usuários desse serviço. As próprias crianças e jovens $(2,1 \%)$ pediram orientação ao SOS Criança. Os pedidos encaminhados por profissionais de instituições de assistência à criança representaram 19,0\% do total. Alguns usuários declararam não ter qualquer vínculo com as crianças $(6,7 \%)$ e outros preferiram ficar no anonimato $(4,6 \%)$. Não há informação sobre a origem de $10,5 \%$ dos contatos.

Um dado significativo é que $28,8 \%$ dos pedidos de orientação (112 casos) referiam-se a situações que envolviam o tema da violência contra crianças e adolescentes, sem qualquer referência a uma situação, um agressor ou uma vítima em particular. Os demais pedidos $(71,2 \%)$ trataram de conteúdos diversos, com destaque para: aconselhamento dos pais quanto a problemas de relacionamento com seus filhos $(13,1 \%)$, procedimentos de adoção ou guarda de crianças $(10,0 \%)$, recolhimento de população de rua $(9,8 \%)$, serviços de saúde $(8,2 \%)$, entre outros. A demanda dos pedidos de orientação envolveu situações que fugiam de sua esfera específica de intervenção, gerando elevado percentual de encaminhamento para outras instituições: 69,9\% desses pedidos foram encaminhados, a maioria para órgãos do sistema judiciário.

Dos 389 pedidos de orientação analisados, 272 $(69,9 \%)$ foram concluídos na mesma data. Essa rapidez pode ser associada ao fato de os pedidos terem sido reencaminhados a instituições mais bem adequadas para atender à solicitação original. Quando a demanda era mais complexa, os pedidos de orientação chegaram a ocupar os técnicos por até 343 dias. Em média, os pedidos foram atendidos em 18 dias (Figura 1). Os casos que permaneceram em atendimento por período mais longo foram os que envolveram pedidos de aconselhamento encaminhados pelos pais.

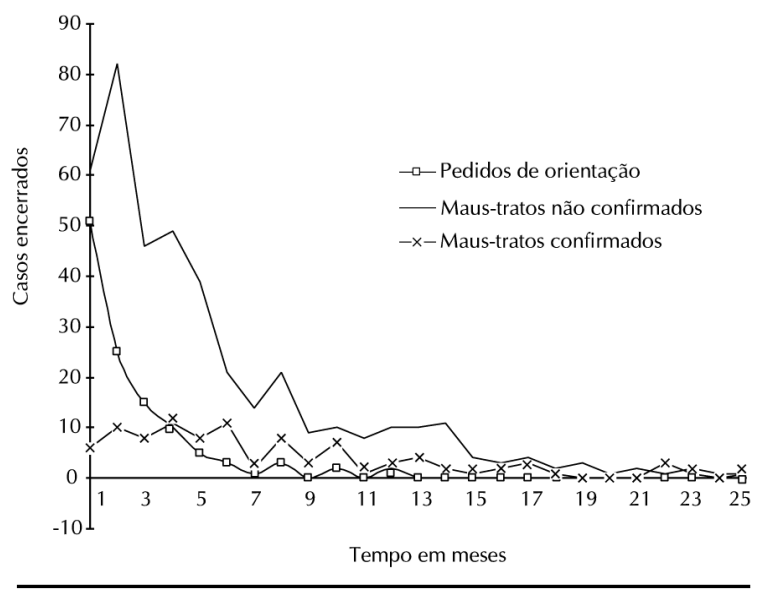

Figura 1 - Duração do tempo de acompanhamento, conforme a natureza dos casos. 
Os pedidos de orientação foram atendidos em $82,0 \%$ dos casos. Foram considerados atendidos os casos para os quais o técnico registrou um encaminhamento ou uma orientação aceitos pelo solicitante. Quando havia registro de que o pedido fugia à área de atuação da Abrapia, sem que houvesse encaminhamento para outra instituição, ou quando o técnico indicou a insatisfação do solicitante, o pedido foi considerado não atendido. Estes representaram 8,7\% do total. Não há informação sobre este item em 9,3\% dos casos.

\section{Denúncias de maus-tratos}

Foram analisadas 587 denúncias de maus-tratos, envolvendo 948 crianças e adolescentes nas várias formas de violência registradas na literatura. Em ordem decrescente de incidência, registraram-se denúncias de abuso físico, negligência, abuso psicológico e abuso sexual. A Figura 2 discrimina os percentuais de abuso confirmados e não confirmados.

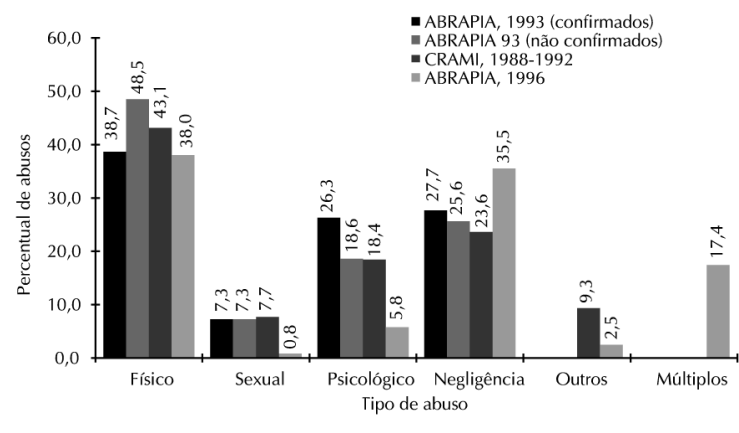

Figura 2 - Comparação entre os tipos de abuso encontrados em três estudos.

Fontes: Deslandes ${ }^{3}$, 1993; Cunha' ${ }^{1}, 1998$

Dentre as 587 denúncias examinadas, $486(82,8 \%)$ não chegaram a se confirmar. Dessas, $239(49,2 \%)$ não foram averiguadas, devido a três razões: 1) não foi possível localizar a residência da criança ou do agressor, seja porque o dado não foi fornecido no telefonema inicial (19 casos), seja porque os técnicos não localizaram o endereço indicado, apesar das várias tentativas (78 casos); 2) a denúncia dizia respeito a casos em que agressor e vítima residiam em outros municípios ou estados (82 casos); 3 ) a denúncia referiase a casos já atendidos por outras instituições (20 casos), ou vinculava-se a situações com as quais o SOS não atua como, por exemplo, divórcios em litígio judicial (9 casos). Outros 31 casos não foram averiguados por motivos variados.

\section{Contato inicial com a Abrapia: o momento da notificação de maus-tratos}

O primeiro contato com o notificante (a pessoa que encaminha a denúncia de maus-tratos) pode-se dar por telefone, por carta, ou pessoalmente. $\mathrm{Na}$ amostra estudada, o telefone foi o recurso mais amplamente utilizado, respondendo por $84,6 \%$ dos casos.

No momento do primeiro contato, o técnico busca saber o meio pelo qual o notificante tomou ciência do trabalho desenvolvido pela Abrapia. Este dado, disponível em 398 formulários, indica que a população conhece a entidade principalmente através do rádio $(38,9 \%)$ e da televisão $(21,9 \%)$. Outros veículos de divulgação têm menor alcance: os notificantes conhecem a Abrapia através de funcionários de instituições públicas $(11,8 \%)$ ou privadas $(3,3 \%)$, pessoas conhecidas $(8,3 \%)$, cartazes $(1,8 \%)$ ou outros meios $(14,1 \%)$.

No contato inicial, é ainda investigada a relação entre o notificante e a criança alvo da denúncia de maustratos. Com maior frequiência, a denúncia é encaminhada por pessoas que têm vínculo familiar $(32,5 \%)$ ou de amizade e vizinhança $(27,6 \%)$ com a criança ou o adolescente. Em 16,7\% dos casos, o notificante escolheu o anonimato. Apenas 4,3\% dos telefonemas tiveram origem em serviços de atenção a crianças. " (Tabela 1).

Os dados mostram que a mãe da criança e seus vizinhos eram os notificantes que, em 1993, ofereciam o maior percentual de denúncias confirmadas.

Tabela 1 - Perfil do notificante da denúncia de maus-tratos

\begin{tabular}{lrrrrrr}
\hline \multicolumn{7}{c}{ Denúncias } \\
\hline Perfil do notificante & \multicolumn{7}{c}{ Não confirmada } & \multicolumn{2}{c}{ Confirmada } & Total \\
\hline Familiares & 141 & 29,01 & 50 & 49,50 & 191 & 32,54 \\
Amigos e vizinhos & 140 & 28,81 & 22 & 21,78 & 162 & 27,60 \\
Anônimo & 84 & 17,28 & 14 & 13,86 & 98 & 16,70 \\
Desconhecido & 26 & 5,35 & 2 & 1,98 & 28 & 4,77 \\
Profissionais de & 22 & 4,53 & 3 & 2,97 & 25 & 4,26 \\
outras instituições & & & & & & \\
A própria criança & 20 & 4,12 & 2 & 1,98 & 22 & 3,75 \\
lgnorado & 29 & 5,97 & 4 & 3,96 & 33 & 5,62 \\
Outros & 24 & 4,94 & 4 & 3,96 & 28 & 4,77 \\
\hline Total & 486 & 100,00 & 101 & 100,00 & 587 & 100,00 \\
\hline
\end{tabular}

\section{Procedimentos de investigação da denúncia}

a) comunicação por via postal: nos 486 casos não confirmados, foi enviada uma média de 0,9 aerogramas por caso, média que se eleva para 2,2 entre os casos confirmados. A correspondência não foi o meio mais usado pelo usuário (agressor ou notificante) para fazer contato com o SOS: entre as 587 denúncias estudadas, apenas 19 cartas foram recebidas.

b) comunicação por telefone: o SOS Criança fez em média 0,4 chamadas por caso, entre as denúncias não confirmadas, e 1,3 para as denúncias confirmadas. O telefone é ainda um meio importante de comunicação da família com o SOS: registraram-se 0,3 ligações em média, entre as denúncias não con-

*Vale lembrar que profissionais das áreas de saúde e educação são obrigados a notificar casos suspeitos ou confirmados de maus-tratos, conforme art. 13, 56 e 245 da Lei $8069 / 90$. 
firmadas, e 1,0 chamada por caso, em média, entre as denúncias confirmadas.

c) entrevistas e visitas domiciliares: entre os casos não confirmados, foram marcadas 442 entrevistas $(0,9$ por caso), e de fato se realizaram $243(0,5$ por caso). Entre os casos confirmados, foram agendadas 237 entrevistas (2,3 por caso), das quais realizaramse 169 (1,7 por caso). A taxa de comparecimento (número de entrevistas realizadas/marcadas) é de 0,5 entre os casos não confirmados, e de 0,7 entre os confirmados. Entre as denúncias não confirmadas, realizaram-se 248 visitas domiciliares e, entre as confirmadas, 97 visitas ( 1,0 por caso).

No presente trabalho, foi chamada ação a qualquer contato estabelecido entre o SOS e a criança, seus familiares e pessoas envolvidas no caso em estudo*. O SOS realizou em 1993, em média, 2,7 ações, para os casos não confirmados, e 4,6 para casos confirmados.

\section{Perfil dos entrevistados}

Durante as investigações da denúncia foram entrevistados adultos, adolescentes ou crianças, conforme a disponibilidade das pessoas envolvidas, a avaliação da necessidade da entrevista pelos técnicos

Tabela 2 - Número de adultos, crianças e adolescentes entrevistados.

\begin{tabular}{|c|c|c|c|c|c|c|}
\hline \multirow{3}{*}{$\begin{array}{l}\text { Local da } \\
\text { entrevista }\end{array}$} & \multicolumn{6}{|c|}{ Entrevistados } \\
\hline & \multicolumn{3}{|c|}{ Casos não confirmados } & \multicolumn{3}{|c|}{ Casos confirmados } \\
\hline & Pai/Resp. & Criança & Adolesc. & Pai/Resp & \multicolumn{2}{|c|}{ Criança Adolesc. } \\
\hline Sede da & 104 & 26 & 9 & 47 & 30 & 29 \\
\hline Abrapia & & & & & & \\
\hline $\begin{array}{l}\text { Visita } \\
\text { domiciliar }\end{array}$ & 103 & 9 & 12 & 17 & 14 & 16 \\
\hline $\begin{array}{l}\text { Sede e visita } \\
\text { domiciliar }\end{array}$ & 23 & - & 2 & 25 & - & 1 \\
\hline Telefone & 2 & - & - & - & - & - \\
\hline Total & 232 & 35 & 23 & 89 & 44 & 46 \\
\hline
\end{tabular}

do SOS e ainda a autorização dos pais para que os filhos fossem ou não entrevistados (Tabela 2).

\section{Duração do acompanhamento das notificações de maus-tratos}

As denúncias de maus-tratos envolveram um expressivo tempo de acompanhamento. Apenas 71 casos puderam ser concluídos em um único dia, e eram todos casos não confirmados de maus-tratos, representando $14,6 \%$ do total de 486 denúncias. Destas, 57 tinham origem em outros municípios ou Estados, e foram imediatamente encaminhadas aos serviços disponíveis nas localidades de origem; 7 foram encaminhadas a outras instituições; em 4 casos o contato imediato com os responsáveis permitiu descartar a denúncia; e uma residência não foi localizada. A informação não esteve disponível em 2 casos.

As denúncias não confirmadas foram acompanhadas em média durante 126,4 dias (mínimo de 1, máximo de 743 dias). Foram examinados 96 casos confirmados (5 registros eram incompletos). $\mathrm{O}$ acompanhamento durou em média 212,5 dias (mínimo de 6, máximo de 749 dias). (Figura 1)

\section{Encaminhamentos para outras instituições}

Na conclusão do caso, o SOS encaminhou-o para instituições que podiam prestar algum tipo de serviço considerado necessário. Foram encaminhadas $30,0 \%$ das denúncias não

Tabela 3 - Instituições para as quais os casos foram encaminhados (respostas múltiplas).

\begin{tabular}{lrrrr}
\hline \multirow{2}{*}{ Instituições } & \multicolumn{5}{c}{ Casos } \\
& $\begin{array}{c}\text { Não confirmados } \\
(\mathrm{N}=146)\end{array}$ & $\begin{array}{c}\text { Confirmados } \\
(\mathrm{N}=117)\end{array}$ \\
& $\mathrm{N}$ & $\%$ & $\mathrm{~N}$ & $\%$ \\
\hline Juiz. da Infância & & & & \\
e Juventude87 & 87 & 59,6 & 37 & 31,6 \\
Atendimento psicológico & 19 & 13,0 & 19 & 16,2 \\
Creches & 1 & 0,7 & 14 & 12,0 \\
Escolas & 4 & 2,7 & 17 & 14,5 \\
Hospitais & 4 & 2,7 & 2 & 1,7 \\
Vara de Família & 7 & 4,8 & 11 & 9,4 \\
Defensoria Pública & 8 & 5,5 & 4 & 3,4 \\
Outros & 30 & 20,5 & 58 & 49,6 \\
\hline
\end{tabular}

confirmadas e $61,9 \%$ confirmadas. A Tabela 3 apresenta as instituições que receberam casos encaminhados pelo SOS.

\section{DISCUSSÃO}

O perfil dos casos de maus-tratos atendidos no SOS Criança indica maior incidência de abuso físico, seguido se negligência, abuso psicológico e abuso sexual. Os percentuais de casos confirmados foram comparados com os encontrados por Deslandes no Crami, no período 1988-1992, e com os encontrados por $\mathrm{Cunha}^{1}$, na Abrapia, em 1996: a ordem de incidência dos diversos tipos de abuso é a mesma (Figura 2).

Em 1993, apenas 17,2\% das denúncias foram confirmadas. Este dado pode estar relacionado a fatores tais como: a) as denúncias partiram da comunidade, e não de algum serviço que já tenha suspeitas tecnicamente fundamentadas; b) havia poucos dados 
disponíveis para que os técnicos prosseguissem na investigação; c) muitas denúncias diziam respeito a crianças e famílias residentes fora do município, o que impossibilitava a investigação.

Em 1996, Cunha ${ }^{1}$ estudou 302 crianças e encontrou $121(40,1 \%)$ casos confirmados. Percebe-se aumento no percentual de casos confirmados, entre 1993 e 1996. Isto pode significar que, no período, tanto a população quanto os técnicos passaram a compreender melhor a dinâmica do fenômeno da violência. Esta hipótese merece ser mais bem investigada em trabalhos futuros, colhendo dados tanto no próprio SOS Criança quanto em serviços similares, de modo a oferecer parâmetros comparativos de análise.

O número de cartas e telefonemas trocado entre a equipe e os entrevistados cresce entre os casos confirmados de maus-tratos, o que indica um estreitamento dos contatos na investigação da denúncia. A média de 4,6 ações por caso (confirmado), encontrada no presente estudo, é similar aos dados do Crami, com 5 ações por caso. Esse dado pode estar articulado ao maior tempo de acompanhamento às denúncias confirmadas. No Crami, cujo trabalho Deslandes ${ }^{2}$ avaliou também com métodos de análise qualitativa, há uma variação importante entre a data da notificação e a data de conclusão. A citada autora sugere que essa variação se deva à receptividade da família em relação aos técnicos ou em relação à orientação que lhes é oferecida. Para aplicar essa hipótese ao caso da Abrapia, outros dados deveriam ser coletados, mas cabe destacar que no presente trabalho foi encontrada também uma variação expressiva no tempo de investigação, similar tanto para os casos confirmados quanto para as denúncias não confirmadas (vide Figura 2).

O notificante é o elemento que torna pública a violência contra a criança ou o adolescente, e pode ser considerado um ator importante na rede de proteção à criança. $\mathrm{O}$ crescimento do percentual de denúncias anônimas entre 1993 e 1996 foi acompanhado, como já visto, por um aumento no percentual de denúncias confirmadas*. Esses dados sugerem que o anonimato pode constituir-se em fator de proteção à criança vítima de maus-tratos, e levam a considerar seriamente a possibilidade de receber denúncias anônimas, motivo de dúvidas em serviços desse tipo.

No entanto, o baixo percentual de confirmação das denúncias sugere de um lado a mobilização da população com o problema e, de outro, que essa população precisa ser mais bem orientada sobre o que, para quem e quando notificar. Futuras campanhas sobre o tema devem abandonar o tom genérico e tratar de estratégias específicas de intervenção sobre o problema. Os veículos mais apropriados são o rádio e a televisão, como indicam os resultados apresentados. Também ficou evidenciada a importância das parcerias institucionais. No caso de denúncias confirmadas, isso parece óbvio: serviços jurídicos deverão dar seguimento aos processos contra o agressor assim como a medidas de proteção à criança; serviços sociais e de saúde deverão, da mesma forma, ser acionados. Mas a parceria é igualmente importante mesmo quando a denúncia não se confirme. O SOS não acompanha os casos, dado que não é este seu perfil, mas com frequiência os técnicos registram que a investigação desenvolvida foi insuficiente para afastar, com segurança, a ocorrência de maus-tratos. $\mathrm{O}$ acompanhamento da família por serviços sociais e/ou de saúde pode ampliar o espectro da intervenção e o benefício gerado para a família e a criança, maximizando os efeitos da ação institucional, além de oferecer dados relevantes para a compreensão do fenômeno da violência contra a criança no Brasil. Como destacou Deslandes ${ }^{3}$, a parceria tem um grande potencial mobilizador, já que a maioria das famílias sobre as quais pesa denúncia de maus-tratos convive com uma grande gama de problemas, derivados de dificuldades socioeconômicas, que desencadeiam ou agravam conflitos intrafamiliares. Por outro lado, o estabelecimento de parcerias institucionais requer uma capacitação especial dos técnicos, já que exige um manejo amplo da estrutura social de serviços.

Em 1993, a própria Abrapia parecia constituir-se em órgão de referência para a questão da violência contra a criança. Observe-se que $28,8 \%$ dos pedidos de orientação referiam-se a situações que envolviam o tema da violência, ainda que não houvesse uma denúncia formal. Pode-se supor assim que, em razão da experiência do SOS Criança, a população e os profissionais de outras instituições recorriam aos técnicos para decidir como agir em casos de maus-tratos.

Os Conselhos Tutelares ainda não estavam operando no Município do Rio de Janeiro, em 1993, o que pode explicar o elevado percentual de encaminhamentos ao Juizado da Infância e da Juventude (na ausência dos Conselhos Tutelares, o encaminhamento deve ser feito ao Juizado, conforme art. 262 da Lei 8069/90). No entanto, o trabalho de Cunha ${ }^{1}$, baseado em dados de 1996, com os Conselhos já em funcionamento, indica que os procedimentos do SOS não sofreram alteração importante, fato referendado pelo discurso dos técnicos do SOS. Dado que os Conselhos são agentes sociais importantes no processo, e começaram a ope-

* Deslandes ${ }^{3}$ encontrou 25,2\% de denúncias anônimas e Cunha' 54,6\%. Neste último, o cálculo foi feito tomando como base o número de crianças envolvidas em uma denúncia; o presente trabalho usa como base a denúncia, que pode englobar várias crianças; essa ressalva, contudo, não invalida a presente discussão. 
rar no Rio de Janeiro em 1996, é possível supor que as relações entre eles e os SOS estejam apenas começando a se estruturar, e que diferenças de procedimentos surjam apenas em futuro próximo.

Destaque-se o número significativo de casos procedentes de outros municípios, em especial da Baixada Fluminense. Este dado vem reforçar a carência de serviços na região, e justifica a recente criação de unidades da Abrapia naquela área, como parte da expansão desses serviços.

A partir dos dados do presente trabalho, é possível sugerir que o funcionamento do SOS, assim como de qualquer serviço que vise os mesmos objetivos,

\section{REFERÊNCIAS}

1. Cunha JM. Atendimento às crianças e adolescentes vítimas de violência doméstica: impasses e desafios [dissertação]. Rio de Janeiro: Fiocruz / Instituto Fernandes Figueira; 1998.

2. Deslandes SF. Maus-tratos na infância: um desafio para o sistema público de saúde. Análise da atuação do Crami Campinas [dissertação]. Rio de Janeiro: ENSP/Fiocruz; 1993. requer treinamento sistemático e permanente de pessoal, instrumento das mudanças aqui identificadas como necessárias.

O primeiro passo nessa direção seria a construção de bancos de dados, permitindo que os serviços sejam permanentemente monitorados, assegurando maior fidedignidade aos dados, e emitindo relatórios periódicos de modo a conferir agilidade à produção de relatórios analíticos" .

\section{AGRADECIMENTOS}

À Abrapia (Associação Brasileira Multiprofissional de Proteção à Infância e à Adolescência), e em particular a Vania Izzo de Abreu, Gerente Geral de Projetos, pelo acesso ao material e pelo apoio na realização deste trabalho.

3. Deslandes SF. Atenção a crianças e adolescentes vítimas de violência doméstica: análise de um serviço. Cad Saúde Pública 1994;10Supl 1:177-87.

4. Kempe $\mathrm{CH}$, Silverman FN, Steele BF et al. The battered child syndrome. JAMA 1962;181:17. 